\title{
Evaluation of the Balance Capability during Rising in the Longitudinal Direction in Elderly People
}

\author{
Hideo HiRAI, ${ }^{*}, *$, Hisao Oка ${ }^{* *}$
}

\begin{abstract}
In this study, balancing capability in the longitudinal direction during rising from the seated position in the elderly was evaluated. In particular, the influence of the rising speed at the moment of leaving the seat, referred to as "seat-off," on balancing capability was examined, since it affects the occurrence of falls. Twenty-eight elderly individuals participated in the study. They were divided into two groups based on their past experience of falls: 19 in the stable rising group and 9 in the unstable rising group. Body movement and the corresponding ground reaction forces during rising motion were measured at two different speeds in each subject, using a motion capture system and a force plate, respectively. From the measurements, "seat-off parameters" that characterize the seat-off motion were obtained. Seat-off parameter values in the stable and unstable rising groups were distributed separately in the seat-off parameter space, forming two distinct clusters. The cluster for the unstable rising group could be further divided into two sub-clusters. The results imply two types of instability during rising from seated position: instability in the forward direction and instability in the backward direction.
\end{abstract}

Keywords: balancing capability, longitudinal direction, seat-off parameters, fall.

Adv Biomed Eng. 5: pp. 13-18, 2016.

\section{Introduction}

According to the 2014 comprehensive survey of living conditions conducted by the Ministry of Health, Labour and Welfare, elderly persons who need assistance or nursing care in activities of daily living (ADL) make up more than $14 \%$ of those injured in falling incidents [1]. As the ability to control the body reduces due to aging and degeneration, the risk of falling at the time of rising becomes higher. In addition, when entering a vicious circle of repetitive falling, the functional ability of the elderly is significantly limited [2-7].

Therefore, to support independent living of the elderly by preventing falling in advance, it is important to avoid the vicious cycle of falling regularly and repetitively [8]. In addition, to avoid being dependent on care or assistance after falling, particularly in the elderly, is a major problem that is currently being faced by the society, and is a characteristic of an ultra-aging society $[9,10]$. Furthermore, according to a report by the Ministry of Health, Labour and Welfare on falling mechanisms in the elderly, there appears to be a higher frequency of falls while standing or walking [1]. It is difficult to determine the specific reason because the number of motion parameters is too large. These parameters include environmental problems and limitations of tests to determine the falling direction during walking.

This study was presented at the Symposium on Biomedical Engineering 2015, Okayama, September, 2015.

Received on August 2, 2015; revised on October 21, 2015; accepted on December 4, 2015.

* Department of Rehabilitation, Faculty of Health Sciences, Hiroshima Cosmopolitan University, Hiroshima, Japan.

** Graduate School of Health Sciences, Okayama University, Okayama, Japan.

\# 3-2-1 Otsukahigasi, Asaminami-ku, Hiroshima, Hiroshima 7313166, Japan.

E-mail: hirai@hcu.ac.jp
However, identification of the tipping direction during rising, rather than during walking, is considered possible, since the motion parameters involved are comparatively less [11]. In other words, kinematic and dynamic analyses are available for measuring the balance capability during rising in the elderly, and aid for preventing falling may be provided by predicting the direction toward which a person tends to fall.

In the past, studies on rising behaviors including seat angles and changes in sitting posture have been pursued to explore the reactivity of a subject to changes in external environmental factors [12-15]. Fewer studies have been performed to examine the actual causes of falls in elderly people, rather than simply looking at the external environment, due to the difficulty of judging the elderly's unconscious environment being different from normal.

For example, in the case of the elderly being in an excited state or in the case that the elderly has a strong desire to void, the person would get up faster than usual. On the contrary, in a situation of decreased arousal, rising is slower than usual. Thus emotional and physiological factors may have a significant effect on the stability of rising. If the rising speed exceeds the allowable capacity of the elder's own rising speed, and there is a change in the person's capability of control in response to the speed of rising, the rising action may become unstable.

In this study, the internal environment as well as the external environment were examined in order to evaluate how the longitudinal balancing capability at varying rising speeds affect falls during rising [16]. In particular, longitudinal balancing capability at seat-off, which is associated with falls, was examined closely $[17,18]$. As a measure of the longitudinal balancing capacity at the time of seat-off, seat-off parameters consisting of center of gravity (COG)-heel horizontal distance and COG horizontal velocity at the time of seat-off, as well as the floor reaction force at seat-off were developed and tested.

\section{Methods}

Twenty-eight healthy elderly persons (13 males, 15 females) aged 
74-92 years who were residents in an elderly nursing home were studied. The ADL level of all subjects was self-care, including outing. Of the 28 elderly persons, 9 had a history of falling more than 2 times ( 4 males, 5 females). These persons were grouped into a unstable rising group. The other 19 persons were grouped into a stable rising group. Experiments were performed as described below. This study was approved by the Okayama University Ethics Committee (approval No. 1824). All subjects received an adequate explanation of the experiment, and only participated in the experiment after giving informed consent.

For the experiment, an armrest-free chair with a seat height equivalent to the lower leg length of the subject was used. The starting limb position was a static sitting posture defined as a hipknee-ankle joint angle of $90^{\circ}$, with the subject's trunk remaining in the vertical position as best as possible. The end limb position was the still standing posture, in which the head and trunk were held in a vertical position. In addition, both hands were placed in front of the chest, and legs apart movement was not allowed. Just before the start of the rising motion, the subject was instructed to rise either as fast as possible or as slowly as possible five times.

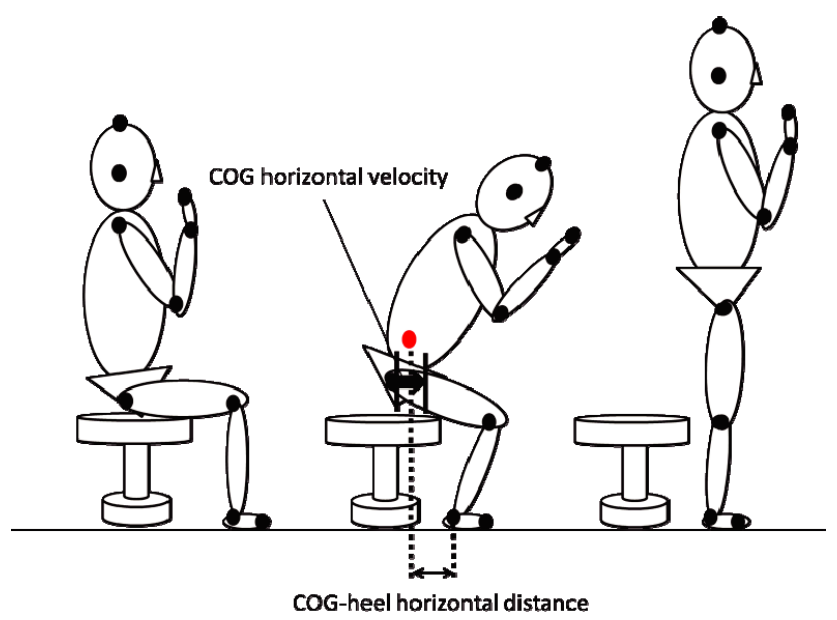

Fig. 1 Definition of COG-heel horizontal distance and COG horizontal velocity.

motion capture systems

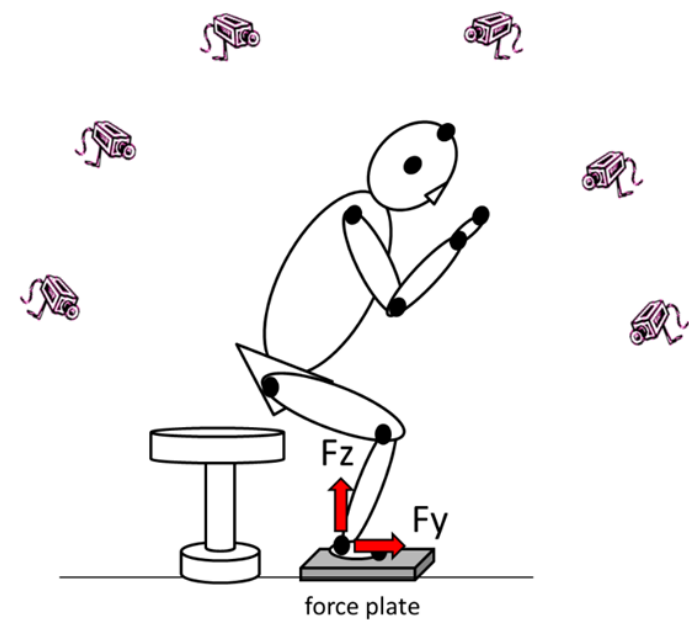

Fig. 2 Motion capture systems and floor reaction force plate.
Each subject performed two tasks; rising at the fastest speed and rising at the slowest speed, in a randomized order.

Image data of the subject at two speeds of rising were acquired and analyzed by a motion capture system (Move-tr./3D, Library Co.). The sampling rate of the images was $50 \mathrm{fps}$. The seat-off parameters consisting of COG-heel horizontal distance and COG horizontal velocity at the time of seat-off were analyzed. The changes in seat-off parameters between the fastest and slowest rising speeds were calculated, in order to examine the association between the parameters.

Markers were affixed at a total of 18 locations: parietal, both ear holes, both acromions, both humerus lateral epicondyles, both radial styloids, both third finger apexes, both greater trochanters, both knee cleft centers, both malleolus lateralis, and both heads of fifth metatarsals. In addition to these points, markers were also placed at the head point, breast point and waist point to calculate the body's center of gravity. The head point is defined as the midpoint between the left and right ear hole markers; the chest point as the midpoint between the left and right acromion markers; and the waist point as the midpoint between the left and right greater trochanter markers. The timing of seat-off was determined by moving image data captured using the analysis software by frame advance reproduction.

The COG-heel horizontal distance at the moment of seat-off was defined as the horizontal distance between the supporting basal plane at the malleolus lateralis and the body's center of gravity. The COG horizontal velocity at seat-off was calculated as the average velocity of the preceding frame and the following

\section{$<$ seat-off parameters $>$}

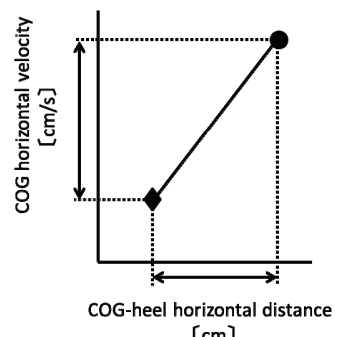

$<$ distribution of seat-off parameters $>$
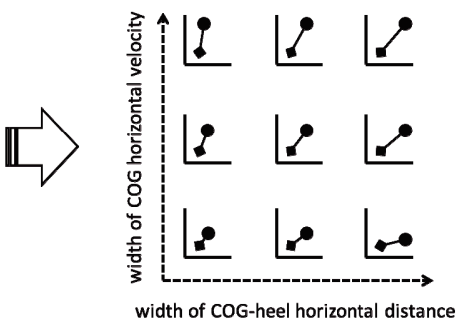

Fig. 3 Schematic diagram of seat-off parameters and the distribution at seat-off.

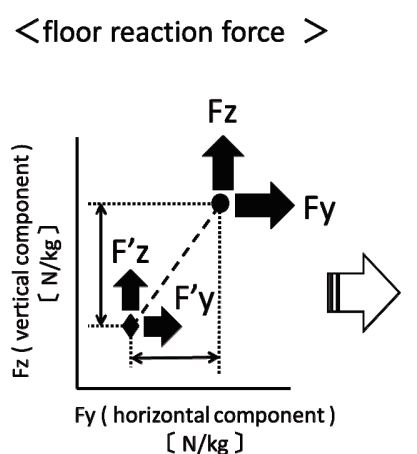
$<$ distribution of floor reaction force $>$

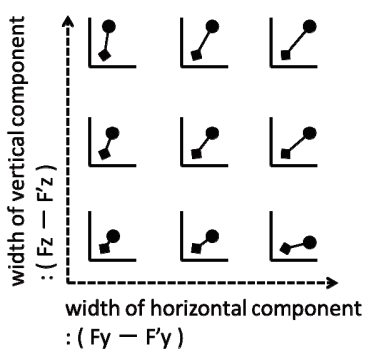

Fig. 4 Schematic diagram of floor reaction force and the distribution at seat-off. 
frame (Fig. 1). The horizontal and vertical components of floor reaction force at the time of seat-off were measured simultaneously using a force plate (CFP03000A, Leptrino) (Fig. 2). The association between the component forces and the changes in seat-off parameters was analyzed.

Seat-off parameters were calculated as the mean COG-heel horizontal distance and the mean COG horizontal velocity of five attempts, for the fastest and the slowest rising speeds. Figure $\mathbf{3}$ shows the definition of seat-off parameters and the distribution of seat-off parameters. The horizontal axis is the change in COGheel horizontal distance between the fastest and the slowest rising speeds, and the vertical axis is the change in COG horizontal distance between the fastest and the slowest rising speeds. Visual inspection of the distribution of the visual seat-off parameters was attempted to assess the longitudinal balancing capability at seatoff. For the floor reaction force at seat-off, the mean horizontal and vertical components of floor reaction force of five attempts were calculated for the fastest and the slowest rising speeds in
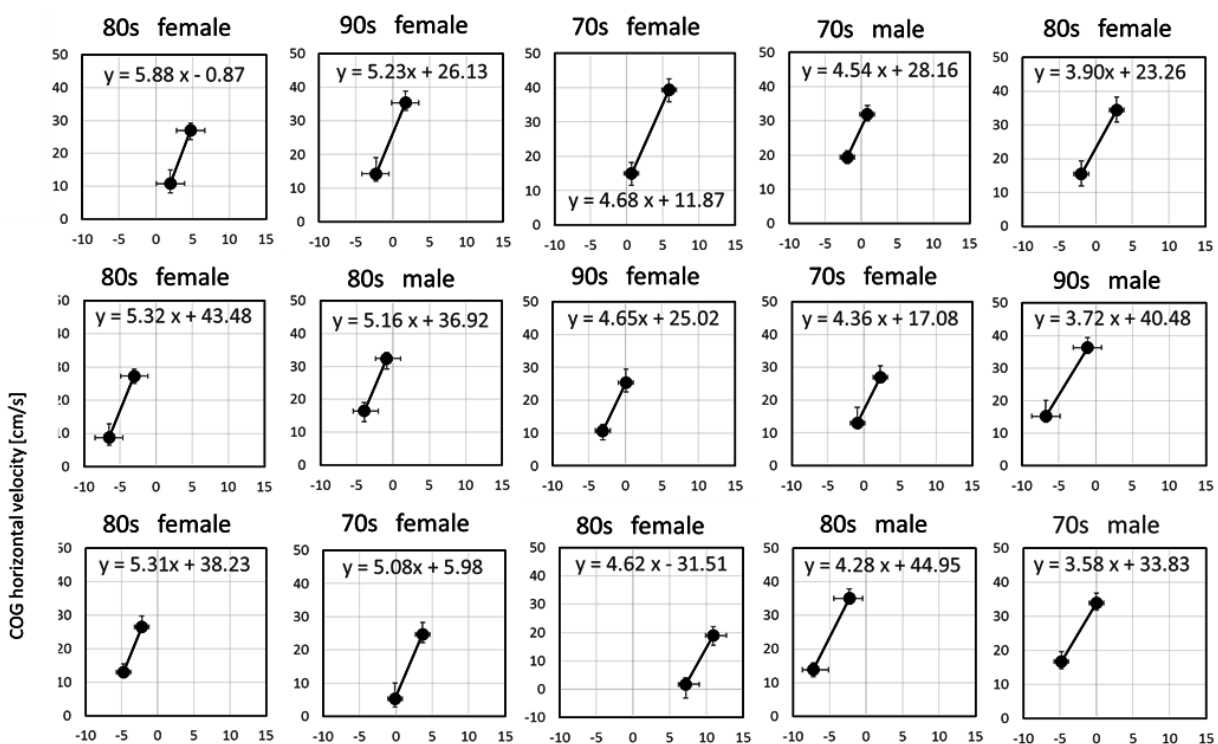

90 s male
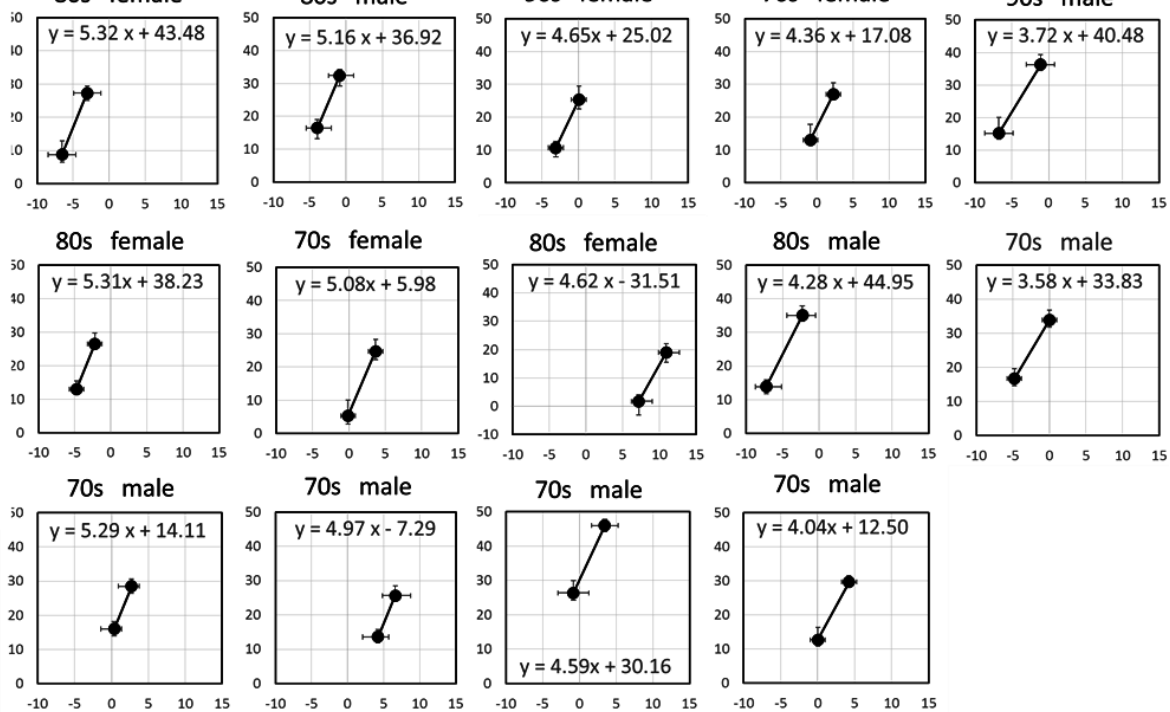

70 s male

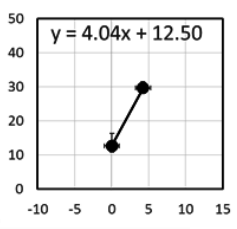

COG-heel horizontal distance $[\mathrm{cm}]$

(a) stable rising group
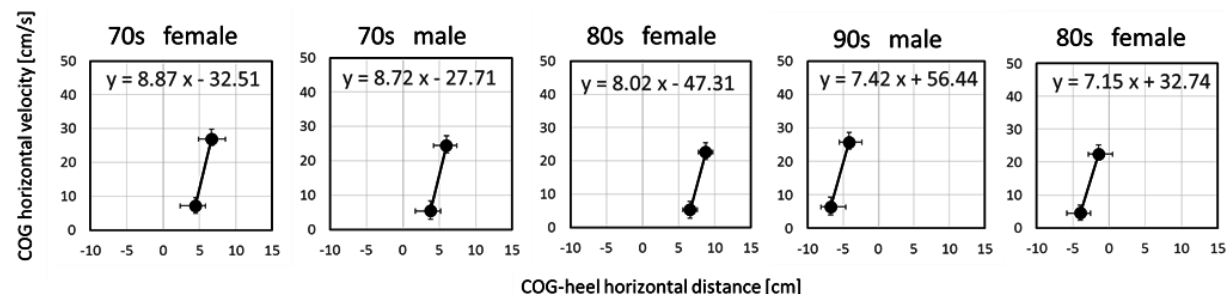

COG-heel horizontal distance $[\mathrm{cm}]$

(b) unstable rising group $\mathrm{A}$
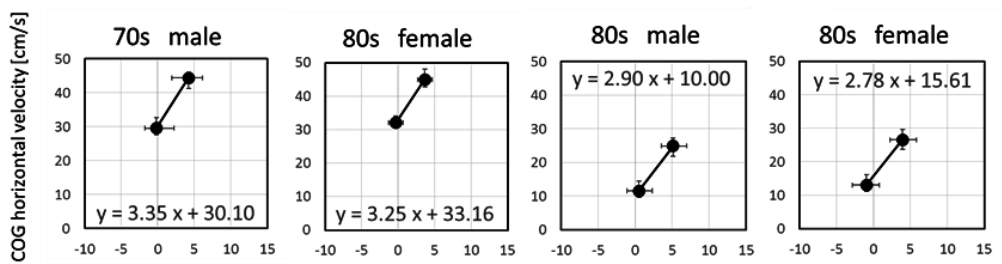

COG-heel horizontal distance $[\mathrm{cm}]$

(c) unstable rising group B

Fig. 5 Seat-off parameters of all subjects. 
each subject. In addition, these mean values were plotted on a graph with the change in horizontal component of floor reaction force between two rising speeds (Fy-Fy) as horizontal axis, and change in vertical component of floor reaction force between two rising speeds $\left(\mathrm{Fz}-\mathrm{F}^{\prime} \mathrm{z}\right)$ as vertical axis. The relation between seatoff parameters was analyzed, and the longitudinal balancing ability at seat-off was verified mechanically (Fig. 4).

\section{Results}

The seat-off parameters of all subjects are shown in Fig. 5. The distribution of seat-off parameters are shown in Fig. 6. The scatter graph of the distribution of seat-off parameters showed that the unstable rising group clustered diagonally, separating the unstable rising groups symmetrically into two sub-clusters of 5 persons and 4 persons each. This result was supported by the experimental

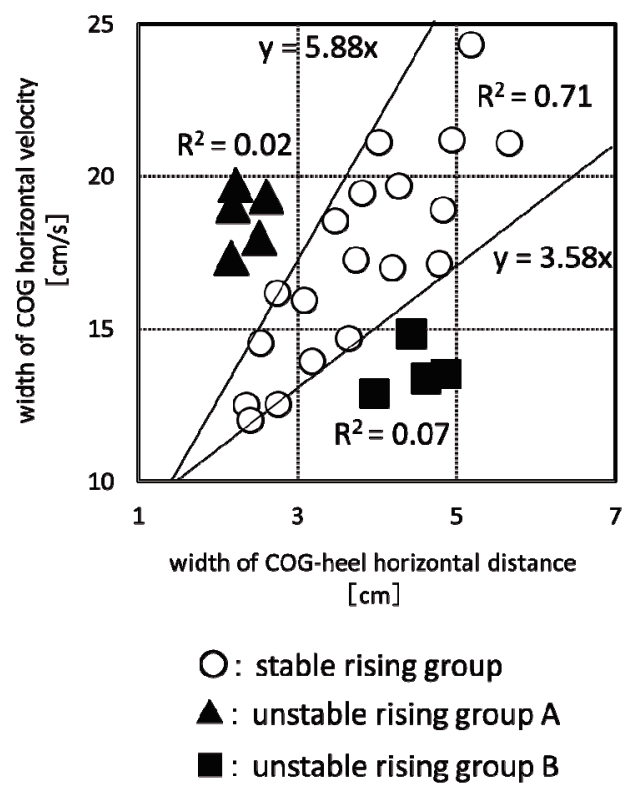

Fig. 6 Distribution of seat-off parameters of all sub jects.

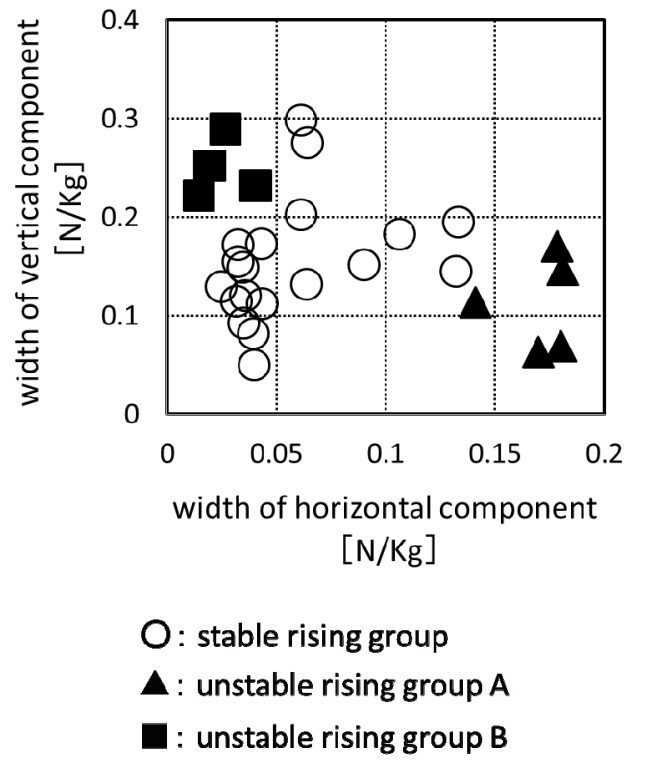

Fig. 7 Distribution of floor reaction forces of all sub jects. results of the floor reaction force distribution obtained by motion analysis (Fig. 7).

The 5-person group in the upper left region were designated the unstable rising group A, and the 4-person group in the right bottom region the unstable rising group $\mathrm{B}$. Including the stable rising group, the three groups were compared with respect to the floor reaction force measurements and the changes in seat-off parameters (Tables 1 and 2). For the changes in seat-off parameters in the three groups, the change in COG-heel horizontal distance at seat-off was compared among three groups using analysis of variance. No significant difference was found among the three groups.

Since the COG horizontal velocity width was significantly different among the three groups, the results were compared using the Ryan method, and the unstable rising group was found to have a significantly smaller velocity than the other two groups. The results of comparison of the floor reaction forces among 3 groups are shown below.

Since the Fy component force for the fastest rising speed varied significantly between three groups, the data were compared using the Ryan method. The force was significantly greater in unstable standing group A than in the other two groups. Since the Fz component force for the fastest rising speed was significantly different between three groups, the data were also compared using the Ryan method. This component force was found to be significantly greater in unstable standing group B than in the other two groups. Since the Fy component force for the slowest rising speed was significantly different among three groups, the data were compared by the Ryan method. The force was significantly greater in unstable standing group B than in the other two groups. As for the $\mathrm{Fz}$ component force for the slowest rising speed, no significant difference was found among three groups.

\section{Discussion}

The distribution of seat-off parameters in the stable rising group (9 males, 10 females) converged within a certain range. The dis-

Table 1 Changes in seat-off parameters at the seat-off.

\begin{tabular}{|c|c|c|}
\hline & $\begin{array}{c}\text { width of COG-heel } \\
\text { horizontal distance }\end{array}$ & $\begin{array}{c}\text { width of COG } \\
\text { horizontal velocity }\end{array}$ \\
\hline unstable rising group A & $2.29 \pm 0.16$ & $18.54 \pm 1.03$ \\
\hline unstable rising group B & $4.47 \pm 0.33$ & $13.03 \pm 1.04^{*}$ \\
\hline stable rising group & $3.78 \pm 0.97$ & $17.21 \pm 3.38$ \\
\hline
\end{tabular}

width of COG-heel horizontal distance; average $[\mathrm{cm}] \pm \mathrm{SD}$,

width of COG horizontal velocity; average $[\mathrm{cm} / \mathrm{s}] \pm \mathrm{SD} p<0.01$

Table 2 Floor reaction force at seat-off.

\begin{tabular}{|c|c|c|c|c|}
\hline & \multicolumn{2}{|c|}{ at fastest } & \multicolumn{2}{c|}{ at slowest } \\
\hline & Fy & Fz & Fy & Fz \\
\hline $\begin{array}{c}\text { unstable rising } \\
\text { group A }\end{array}$ & $0.29 \pm 0.02^{*}$ & $1.18 \pm 0.02$ & $0.12 \pm 0.04$ & $1.07 \pm 0.01$ \\
\hline $\begin{array}{c}\text { unstable rising } \\
\text { group B }\end{array}$ & $0.22 \pm 0.08$ & $1.28 \pm 0.04^{*}$ & $0.19 \pm 0.01^{*}$ & $1.05 \pm 0.03$ \\
\hline $\begin{array}{c}\text { stable rising } \\
\text { group }\end{array}$ & $0.19 \pm 0.02$ & $1.23 \pm 0.02$ & $0.14 \pm 0.03$ & $1.07 \pm 0.02$ \\
\hline
\end{tabular}


tribution of seat-off parameters in the remaining two groups (4 males, 5 females) deviated from this range, especially in those who reported more than two fall experiences in a survey conducted during the previous year. While a strong positive correlation was observed between the COG-heel horizontal distance and the COG horizontal velocity in the stable rising group, no correlation was observed in the unstable rising group. In this experiment, when analyzing the results of the distribution of seat-off parameters of the three groups, the corresponding property was found to be necessary for changes in rising speed.

In the stable rising group, in order to obtain stability at seatoff corresponding to the rising speed, presumably the COG horizontal velocity should be controlled by adjusting the COG-heel horizontal distance and the body should be stabilized by maintaining the COG position within the supporting basal plane. Additionally, for those with seat-off parameters distributed in the lower left region, when the distance between the slowest and fastest rising speed is short, the possible range of rising action would be very limited. Conversely, for those with seat-off parameters distributed in the upper right region, when distance between the slowest and fastest speed is long, the possible range of rising actions would be very broad.

On the other hand, disturbed balance of COG-heel horizontal distance and COG horizontal velocity during seat-off may not act reciprocally in the unstable rising group, implying that this is the cause of instability. In other words, when the COG-heel horizontal distance and the COG horizontal velocity vary while maintaining a proportional relationship within a fixed range, this mechanism leads to stability in rising. However, when deviated from that range, rising becomes unstable. The fact that the distribution of seat-off parameters in the unstable rising group A was displaced to the upper left side of the stable rising group inferred a tendency of excessive dependence on the COG horizontal velocity to respond to changes in rising speed.

Similarly, the distribution of seat-off parameters in unstable rising group B was displaced to the lower right side of the stable rising group, implying a tendency of excessive dependence on the COG-heel horizontal distance to respond to changes in standing speed. The experimental seat-off parameters in the stable rising group was distributed within the range of $y=5.88 \mathrm{x}$ and $\mathrm{y}=3.58 \mathrm{x}$, while the seat-off parameters in unstable rising group A and unstable rising group B deviated from this range.

In addition, the potential characteristics at the time of rising in the unstable rising group were analyzed from the change in seat-off parameters and the floor reaction force. The seat-off parameters in unstable rising group A ( 2 males, 3 females) had the smallest change in COG-heel horizontal distance and greatest change in COG horizontal velocity among the three groups. For the floor reaction force, the Fy component force at the fastest rising speed was significantly larger than those in the other two groups.

These findings infer that unstable rising group A has a tendency to lose balance in a forward direction, especially when attempting to rise quickly. Among the three groups, the seat-off parameters in unstable rising group B (2 males and 2 females) exhibited the greatest change in COG-heel horizontal distance and the smallest change in COG horizontal velocity. In addition, the Fz component force at the fastest rising speed and the Fy component force at the slowest rising speed were significantly greater

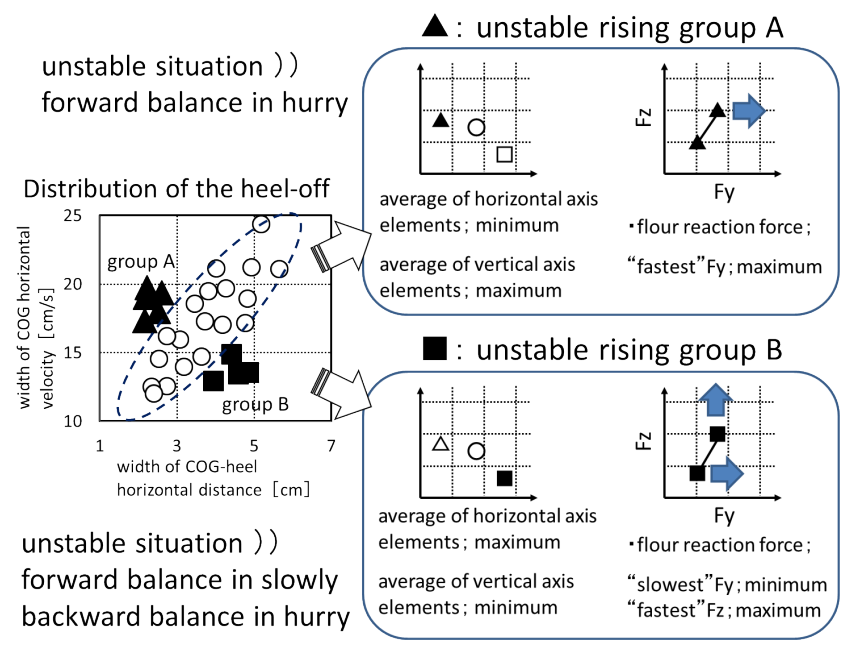

Fig. 8 Features of instability at the time of standing in the 2 unstable rising groups.

than those in the other two groups. From these results, the following tendencies are speculated.

The unstable rising group B is likely to lose balance in the rear direction when rising particularly quickly, and is likely to lose balance in the forward direction when attempting to rise slowly (Fig. 8).

\section{Conclusion}

An evaluation of longitudinal balancing capacity during rising in the elderly was attempted:

(1) Seat-off parameters consisting of the COG-heel horizontal distance and COG horizontal velocity at seat-off were developed.

(2) Longitudinal balancing ability could be assessed by analyzing the distribution of seat-off parameters.

(3) Floor reaction forces at the time of seat-off were verified.

As a result of the above evaluation, elderly subjects exhibiting instability during rising were divided into two groups, and the following characteristics were revealed during rising:

(1) Unstable balance in the forward direction: There was instability in forward balance, especially when attempting to rise in a hurry.

(2) Unstable balance in the rear direction: Instability in backward balance exists when attempting to rise in a hurry, and instability in forward balance when trying to rise slowly.

\section{References}

1. Ministry of Health, Labour and Welfare: The comprehensive survey of living conditions 2014.

2. Kannus P, Palvanen M, Niemi S, Parkkari J, Natri A, Vuori I, Järvinen M: Increasing number and incidence of fall-induced severe head injuries in older adults: nationwide statistics in Finland in 1970-1995 and prediction for the future. Am J Epidemiol. 149, pp. 143-150, 1999.

3. Kanae K, Ryoko K, Yumi H, Manami T, Yuko N, Yasuo N: Prognostic validity of executive function and injurious fall history in evaluating injurious fall risk among frail elderly people. Journal of Rehabilitation and Health Sciences. 8, pp. 23-28, 2010. (In Japanese)

4. Leveille SG, Penninx BW, Melzer D, Izmirlian G, Guralnik JM: 
Sex differences in the prevalence of mobility disability in old age: the dynamics of incidence, recovery and mortality. J Gerontol B Psychol Soc Sci. 55, pp. 41-50, 2000.

5. Brooks SV, Faulkner JA: Skeletal muscle weakness in old age: underlying mechanisms. Med Sci Sports Exerc. 26, pp. 432-439, 1994.

6. Sieri T, Baretta G: Fall risk assessment in very old and females living in nursing homes. Disabil Rehabil. 12(12), pp. 718-723, 2004.

7. Tinetti ME, Speechley M, Ginter SF. Risk factors for falls among elderly persons living in the community. N Engl J Med. 319, pp. 1701-1706, 1988.

8. Tinetti ME, Richman D, Powell L: Falls efficacy as a measure of fear of falling. J Gerontol. 45, pp. 239-243, 1990.

9. Tinetti ME, Mendes de Leon CF, Doucette JT: Fear of falling and fall-related efficacy in relationship to functioning among community-living elders. J Gerontol. 49(3), pp. 140-147, 1994.

10. Kinugasa $T$, Nagasaki H, Ito H, Hashizume H, Furuna $T$, Maruyama H: Effect of aging on motor ability in men aged 18 to 83 years. Jpn J Phys Fitness Sports Med. 43, pp. 343-351, 1994.

11. Arai T, Shiba Y, Watanabe S, Shibata H: The relationship between the stride time variability, motor ability and fall in community-dwelling elderly people. Japanese Physical Therapy Association. 38(3), pp. 165-172, 2011.

12. Burdett RG, Habasevich R, Pisciotta J. Biomechanical comparison of rising from two types of chair. Phys Ther. 65, pp. 1177 $1183,1985$.

13. Vander LDW, Brunt D, McCulloch MU: Variant and invariant characteristics of the sit-to-stand task in healthy elderly adults. Arch Phys Med Rehabil. 75, pp. 653-660, 1994.

14. Alexander NB, Schultz AB, Warwick DN: Rising from a chair: Effects of age and functional ability on performance biomechanics. J Gerontol. 46, pp. 91-98, 1991.

15. Schenkman M, Riley PO, Pieper C: Sit to stand from progressively lower seat heights-alterations in angular velocity. Clin Biomech. 11(3), pp. 153-158, 1996.

16. Shumway-Cook A, Woollacot MH: Motor control. Lippincott Williams \& Wilkins. pp. 4-5, 2007.

17. Schenkman ML, Berger RA, Riley PO: Whole-body movements during rising to standing from sitting. Phys Ther. 70(10), pp. 638-648, 1990.

18. Hughes MA,Weiner DK,Schenkman ML et al.: Chair rise strategies in the elderly. Clin Biomech. 9, pp. 187-192, 1994.

\section{Hideo HiraI}

He received the M.S. degree in Health and Welfare from Prefectural University of Hiroshima in 2010. He is currently a student of a doctor's course in the graduate school of Health Sciences, Okayama University. Since 2014, he has been an Lecturer in the Department of Rehabilitation, Hiroshima Cosmo-

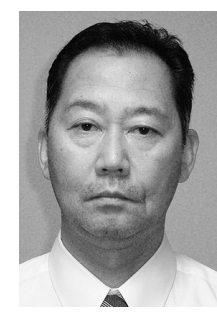
politan University. He engages in biomechanics and motor development. He is a member of J SMBE, JES, JSCB and SOBIM.

\section{Нisao ОкА}

Dr. Ніsаo Ока received his B.E. and M.E. degrees in electrical engineering from Okayama University, Japan, 1976 and 1978, respectively, and completed his D.Eng. degree in biomechanical measurement at Osaka University in 1988. He is presently a professor in the graduate school of

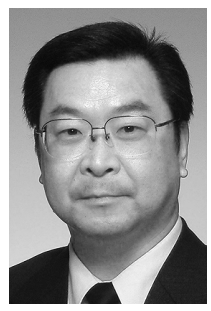
Health Sciences, Okayama University. He is currently interested in measurements and applications of biomechanical properties, and functional assessments of muscle contraction, with application in sport and rehabilitation. 